\title{
Modeling the Phase Transition Associated with Melting Snow in a 1D Kinematic Framework: Sensitivity to the Microphysics
}

\author{
J. A. Milbrandt, ${ }^{1}$ J. Thériault, ${ }^{2}$ and R. $\mathrm{Mo}^{3}$
}

\begin{abstract}
A simple 1D kinematic cloud model coupled to a two-moment bulk microphysics scheme is used to perform quasiidealized simulations of snow, with a prescribed upper boundary snow field based on observed radar reflectivity and temperature, falling into a low-level melting layer. The model realistically simulates the formation of a nearly isothermal layer below the melting level, the surface precipitation rate, and the phase transition from liquid to solid, consistent with observations for this case. A series of test runs is performed to examine the sensitivity of modeling the timing and duration of the phase transition period to details of specific parameterization aspects related to snow in the microphysics scheme. The sensitivity tests include varying the number of prognostic moments, the mass-diameter relation, the fall velocity-diameter relation, the treatment of aggregation, and the lower limit for the slope of the size distribution. It is shown that the simulated transition period, for such a case with the initial melting level being close to the surface, can be quite sensitive to model parameters specified within realistic ranges and/or ranges within our physical understanding.
\end{abstract}

\section{Introduction}

Wintertime precipitation forecasting using numerical weather prediction (NWP) models is inherently challenging due to the need to account for a complex series of physical processes that ultimately lead to surface precipitation. For situations where the melting level is close to the surface, the prediction of the precipitation phase and timing of a phase transition is particularly challenging. The treatment of the melting of snow in the model affects the low-level

\footnotetext{
1 Atmospheric Numerical Prediction Research, Environment Canada, Montreal, Canada. E-mail: jason.milbrandt@ec.gc.ca

2 Université de Québec à Montréal, Montreal, Canada.

3 National Laboratory for Coastal and Mountain Meteorology, Environment Canada, Vancouver, Canada.
}

temperature structure, and hence feeds back to the calculation of the melting rate. In mountainous regions, the diabatic cooling from melting snow can induce downward air motion and result in significant changes to the surface flow field. The ability of a model to simulate these effects depends on a number of factors, including the details in the representation of precipitation.

During the Vancouver 2010 Winter Olympic and Paralympic Games, held in the Vancouver-Whistler region at the south coast of British Columbia (BC), Canada, accurate prediction of precipitation phase and intensity was critical for many of the venue managers. Forecasting in this region was particularly challenging due to the complex terrain and warm coastal weather conditions. In support of this, Environment Canada ran a special high-resolution (1-km horizontal grid spacing) configuration of the global environment multiscale (GEM) NWP model to provide specialized, detailed guidance on precipitation and other meteorological fields (МАILHOT et al., 2012).

Weather centers are moving quickly towards running operational NWP models at this so-called "cloud resolving" scale. In such configurations, cloud microphysical and precipitation processes are parameterized using a bulk microphysics scheme (BMS). The full range of hydrometeors is partitioned into several categories, each with common characteristics such as terminal fall velocities and bulk densities. The particle size distribution for each category is represented by an analytic function. One or more moments of the distribution, each proportional to some physical quantity (e.g. the mass content), are predicted by tendency equations for individual microphysical processes. Current BMS are either 
one-moment (e.g. Lin et al., 1983; WalKo et al., 1995; Thompson et al., 2004'1), two-moment (e.g. Ferrier 1994; Meyers et al., 1997; SEIFERT and Beheng 2001; Morrison and Milbrandt 2005), or three-moment (MilbrandT and Yau 2005a, b).

Numerous studies have illustrated that results can vary considerably using different schemes (e.g. LiU and Colle 2011; Morrison and Milbrandt 2011; Wu and Petty 2010). Even with the same scheme, the results can be sensitive to the number of prognostic moments (e.g. Milbrandt and Yau 2006; Morrison et al., 2009; MilBRANDT et al., 2010). The implicit conclusion from many of these studies has been that with increasing complexity of the BMS comes increased realism. However, some recent studies have highlighted the sensitivity to specific assumption made in the parameterization of specific processes. For example, Morrison and Milbrandt (2011) compared idealized supercell simulations using two comparably detailed two-moment BMSs and found considerable sensitivity of the simulated storms to the specific model treatment of high-density ice (graupel and hail) and to the parameterization of raindrop breakup. Their recommendation was that since there is inherent uncertainty in the parameterization of many specific processes, it is crucial to understand the uncertainty and the range of possible results if one is to use such a tool to its maximum benefit, either for processes studies or for NWP.

In regions of complex orography, high-resolution models can resolve the detailed flow and thus have the potential to simulate the precipitation processes with accuracy. When the melting level is near the surface and diabatic processes can affect the lowlevel flow, it is particularly important to understand the potential model errors. For the microphysics scheme, it is important to understand specifically the sensitivity to assumptions made in the treatment of the snow melting process. Other physical processes, such as rain evaporation, may also play important roles in such situations but we restrict our focus in this study to the treatment of snow. This article therefore seeks to examine, through simple 1D kinematic model simulations using a two-moment

1 The most recent version of the Thompson BMS is twomoment for the ice and rain categories.
BMS, the sensitivity of some basic assumptions in the parameterization of snow to the diabatic cooling and surface precipitation phase change for a situation with snow falling though a near-surface melting layer.

The article is organized as follows. Section 2 describes a case of heavy snowfall and down slope flow, likely diabatically-induced, that was observed during the Vancouver 2010 Winter Olympics. Section 3 describes the simple 1-dimensional (1D) kinematic framework used in this study. Section 4 presents the results of a series of sensitivity tests with the model microphysics scheme, aimed at illustrating the sensitivity to the simulation of the precipitation phase changes. Discussion on the implications for improving BMSs and for the potential utility of a simple 1D modeling system as a forecast tool is provided in Sect. 5. Concluding remarks are given in Sect. 6.

\section{Case Overview}

During the first weekend of the 2010 Vancouver Games (13-14 February 2010), heavy precipitation event occurred as an intense frontal system, associated with a deep large-scale low pressure system over the North Pacific Ocean, swept across coast of BC. Widespread snow was reported on Whistler Mountain with periods of rain at the base. Figure 1 depicts the local orography in the vicinity of Whistler Mountain, along with the locations of several special weather stations that were set up for the 2010 Games, including a Doppler weather radar, located at the VVO site. This special set of instrumentation was deployed as part of the Science of Nowcasting Winter Weather for Vancouver 2010 (SNOW-V10) research demonstration project (IsAAC et al., 2012). Details of the instrumentation can be found in JOE et al. (2012) and Gultepe et al. (2012). Radar reflectivities and Doppler wind velocities along the cross-section towards Whistler Mountain, indicated by the dashed line in Fig. 1, are shown for 0000 and 0300 UTC 14 February in Fig. 2. During the storm, the effects of warm air advection competed with diabatic cooling from melting snow as it fell through the melting layer. The 0000 UTC sounding at VOC (Fig. 3a) 


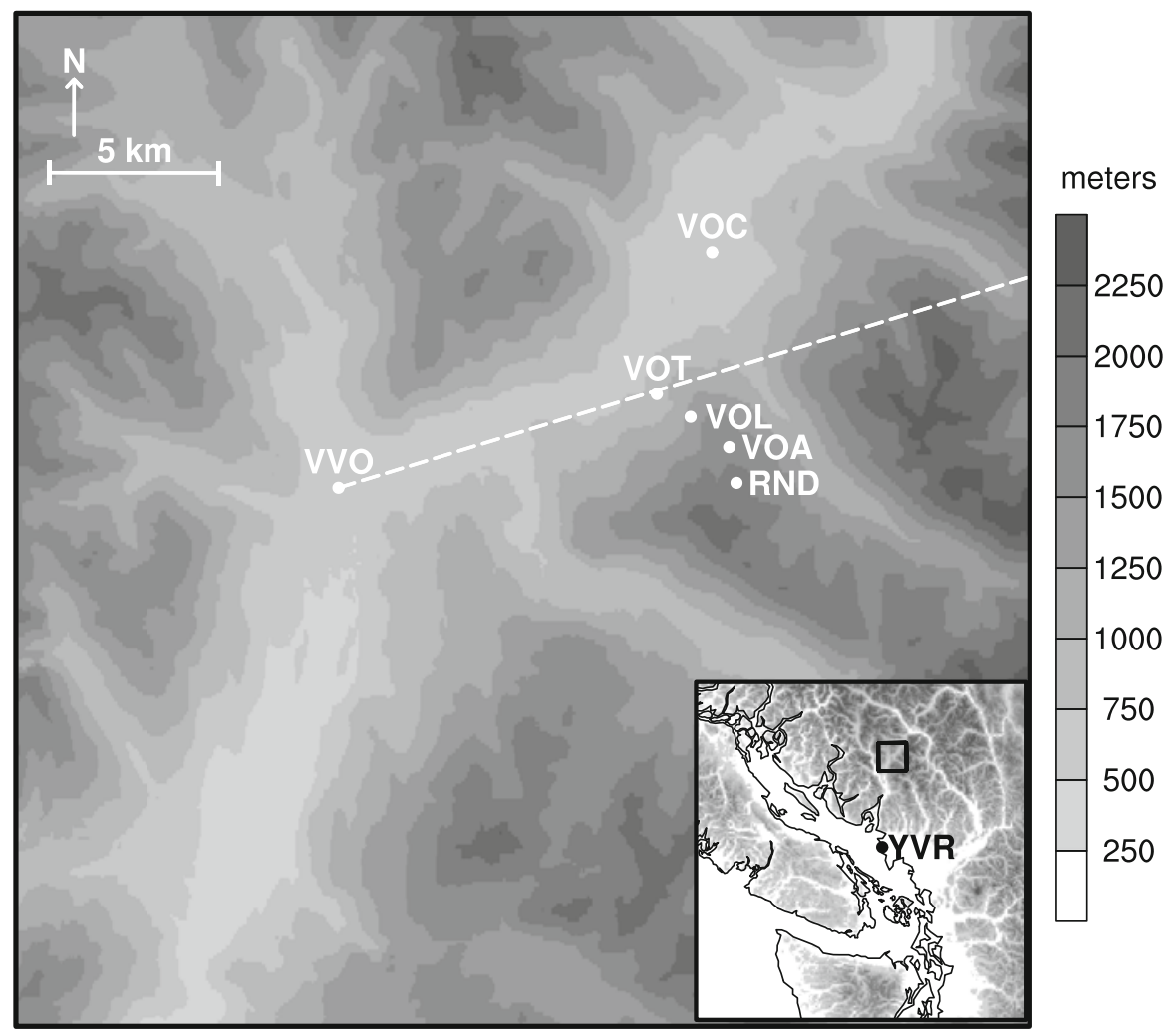

Figure 1

Orography in the Whistler Mountain region with station locations (inset is a larger map of the regions, indicating location of the main figure; YVR is the Vancouver International Airport). The Whistler weather radar is located at the VVO station. Dashed line denotes location of vertical radar cross-sections shown in Fig. 2

indicates that the freezing level (i.e. the $0{ }^{\circ} \mathrm{C}$ level) was quite close to the ground at that time, approximately $500 \mathrm{~m}$ AGL (above ground level) at that station. A nearly isothermal layer was formed by 0600 UTC (Fig. 4b) and there was a shift of the valley-mountain flow from upslope to downslope by 0300 UTC, as indicated by the change in the Doppler wind direction from away from the radar at 0000 UTC (indicated by red in the lowest few $100 \mathrm{~m}$ AGL in Fig. 2b) to towards the radar (indicated by blue in the lowest levels in Fig. 2d). It is hypothesized that this was induced by diabatic cooling from melting snow (ThÉRIAUlt et al., 2012). Given the well-documented observations of this case (ThÉRIAUlt et al., 2012), this is an excellent case to examine the simulation of the phenomena addressed in this study.

The precipitation phase at sites with various elevations along Whistler Mountain varied throughout the precipitation period. Figure 4 depicts the precipitation rate measured from the FD12p optical sensor (JoE et al., 2012; GultePe et al., 2012) at the VOT station, located at the base of Whistler Mountain (Fig. 1), along with the measured surface temperature, which dropped approximately $5{ }^{\circ} \mathrm{C}$ at around 2100 UTC 13 February to $1{ }^{\circ} \mathrm{C}$ (by around 0300 UTC 14 February) as melting precipitation cooled the air below the melting level. At higher stations (not shown), the surface temperature dropped to $0{ }^{\circ} \mathrm{C}$. Further details of the case, including an analysis of the precipitation phase and intensity, temperature, wind speed and direction can be found in THÉRIAUlt et al., (2012). We remark that the precipitation rate was observed to vary considerably with elevation along Whistler Mountain for this case (GULTEPE et al., 2012). Nevertheless, Fig. 4 gives an indication of the timing and magnitude of the surface precipitation rates in that region. 

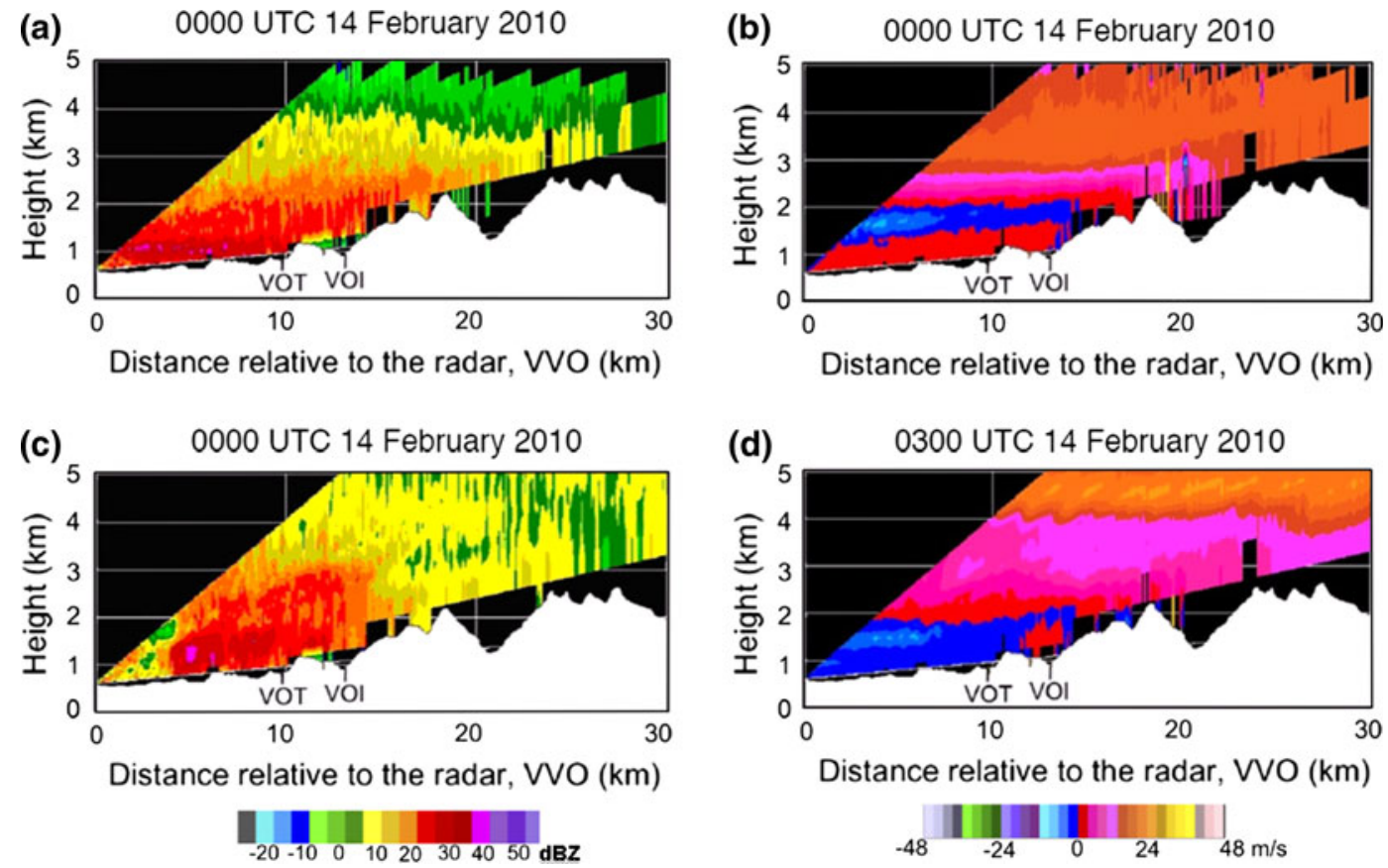

Figure 2

Observed radar reflectivity (left) and Doppler wind velocity (right) at 0000 UTC (top) and 0300 UTC (bottom) 14 February 2010 from the Whistler radar for vertical cross-section depicted by the dashed line in Fig. 1. For the Doppler winds, warm (cold) colors denote wind away from (towards) the radar
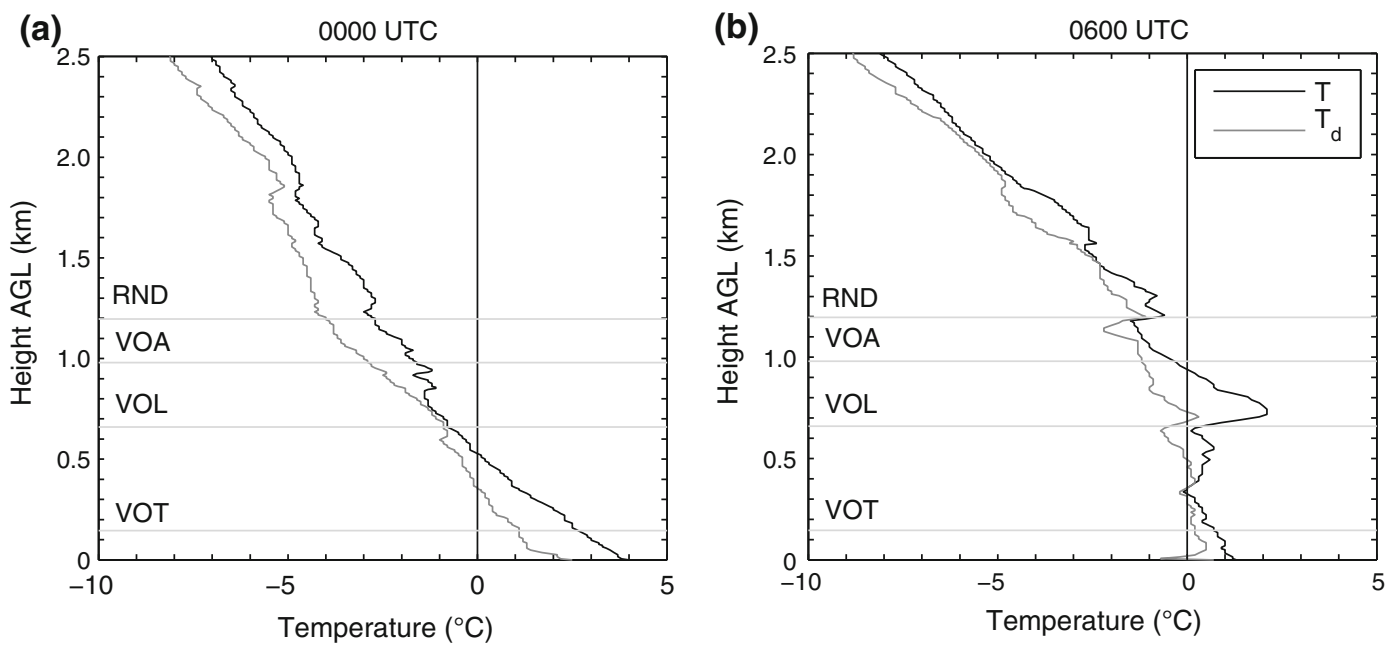

Figure 3

Observed soundings at a 0000 UTC and b 0600 UC 14 February 2010 at VOC, near Whistler Mountain (location indicated in Fig. 1)

Observational data from this case were used to initialize an idealized 1D kinematic model (described below) using the same microphysics scheme as in the high-resolution NWP model that was run operationally during the Vancouver 2010 Games. Through numerical experiments, the sensitivity to assumptions in the microphysics on the simulated surface temperature and precipitation phase and intensity are explored. 

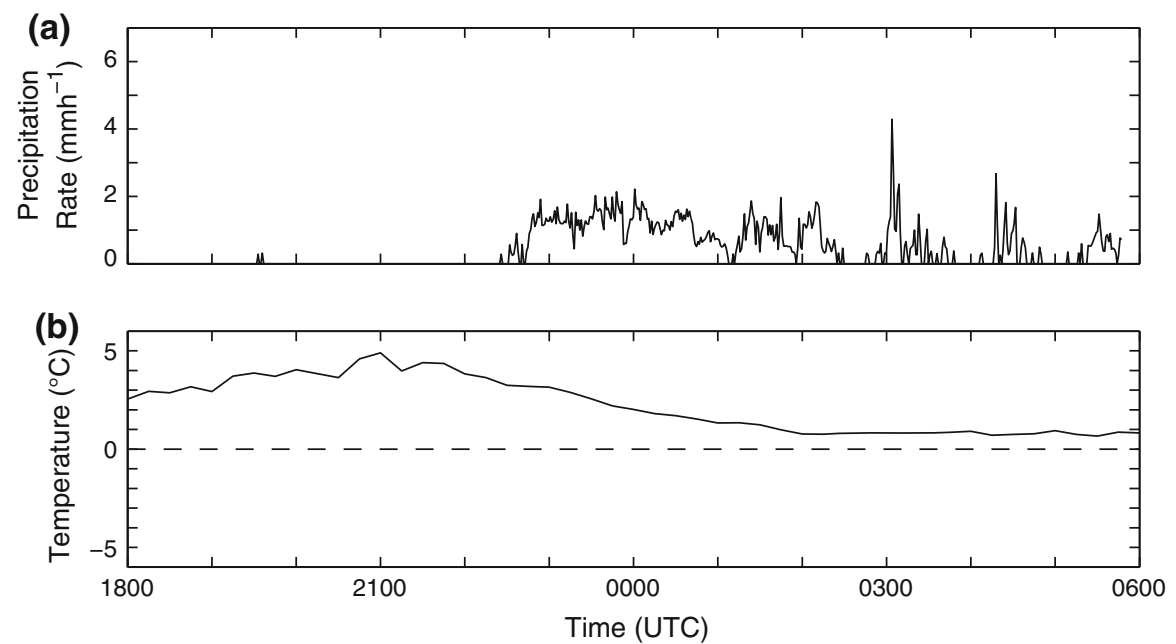

Figure 4

a Precipitation rate measured from the FD12P optical sensor, and b observed temperature at VOT station near the base of Whistler Mountain (location indicated in Fig. 1). Note, precipitation rate data is missing after approximately 0545 UTC due to power outage

\section{Description of Modeling System}

The modeling system used in this study is a simple 1D kinematic cloud model coupled to the two-moment version of the Milbrandt and YAU (2005a, b) microphysics scheme (hereafter referred to as MY2), the same BMS used in the real-time, highresolution NWP runs during the 2010 Games. The 1D model was initialized with a single sounding, a prescribed snow field above the melting level, and a zero vertical motion field. Details of the 1D model are given in "Appendix 1"; an overview of the MY2 scheme is given in "Appendix 2". For the simulations in this study, the model top was at $1,640 \mathrm{~m}$ AGL with 47 evenly-spaced levels, with a vertical grid spacing of $35 \mathrm{~m}$, and a time step of $10 \mathrm{~s}$. Note that for high-resolution mesoscale models typically use unevenly-spaced vertical levels and with larger spacing (except for the levels nearest the surface, where a vertical spacing of $35 \mathrm{~m}$ is typical) while a time step of $10 \mathrm{~s}$ is comparable to that for a NWP model running at the $\mathrm{km}$ scale. ${ }^{2}$

2 The 1-km version of GEM run for the 2010 Vancouver Games used a time step of $30 \mathrm{~s}$ (MAILHOт et al., 2012). However, models using an Eulerian advection scheme will typically use a time step of $10 \mathrm{~s}$ or less for this horizontal grid spacing.
A series of simulations were run in order to examine the evolution of the temperature profile and precipitation phase transition as snow falls through the melting layer and to study the sensitivity of this set of processes on different assumptions in the microphysics scheme. The model was initialized with the observed sounding 0000 UTC 14 February 2010 at the VOC station (Fig. 3a; see Fig. 1 for station location). A snow field was prescribed at all times at 1,600 m AGL, above the initial melting level, approximately $500 \mathrm{~m}$ AGL, and allowed to fall and evolve according to the microphysics scheme. Each simulation was integrated for $8 \mathrm{~h}$ in order to ensure that the entire precipitation phase transition period is captured.

The prognostic model variables for snow are the mass mixing ratio $\left(q_{\mathrm{s}}\right)$ and total number concentration $\left(N_{\mathrm{s}}\right)$. The initial and upper boundary conditions for the snow field are obtained by prescribing $q_{\mathrm{s}}$ and $N_{\mathrm{s}}$ at the highest model level, based on the observed radar reflectivity of $25 \mathrm{dBZ}$ at 1,600 $\mathrm{m}$ AGL at the VOT station (Fig. 2a) and the air temperature of $-5{ }^{\circ} \mathrm{C}$ at that level, based on the sounding at VOC (Fig. 3a) The values of $q_{\mathrm{s}}=0.45 \mathrm{~g} \mathrm{~kg}^{-1}$ and $N_{\mathrm{s}}=3,115 \mathrm{~m}^{-3}$ are obtained (see "Appendix 3" for details). Note that in this study we focus on melting snow, thus the initial hydrometeor field is prescribed to be snow only, with no cloud liquid water and zero vertical motion. 


\section{Results}

\subsection{CTR Simulation}

The specifications of the control simulation (CTR) and sensitivity experiments (EXP1-EXP9) are summarized in Table 1; parameter settings for snow for CTR are listed in Table 2. The results from CTR are summarized in Fig. 5 with time-height diagrams of the snow and rain mixing ratios $\left(q_{\mathrm{s}}\right.$ and $q_{\mathrm{r}}$, respectively), the ambient temperature $(T)$, the diabatic cooling rate due to melting, and time series of the liquid and solid precipitation rates $\left(R_{\text {liquid }}\right.$ and $R_{\text {solid, }}$, respectively) and the surface temperature, $T_{\text {sfc }}$ (i.e at the lowest model level). The snow sediments from its initial level towards the surface and begins to melt to rain once it reaches $500 \mathrm{~m}$ AGL, approximately $15 \mathrm{~min}$ into the simulation. The temperature below the melting level starts decreasing at this time as a result of the diabatic cooling from the melting, which increases in intensity and decreases in elevation as more snow penetrates further below the melting level. The first precipitation reaches the ground after

Table 1

List of sensitivity runs

\begin{tabular}{|c|c|}
\hline Experiment & Description \\
\hline CTR & $\begin{array}{l}\text { Control run; baseline two-moment MY2 } \\
\text { configuration (see Table 2) }\end{array}$ \\
\hline EXP1 & One-moment for snow \\
\hline EXP2 & $\begin{array}{l}m-D \text { parameters }\left[c_{\mathrm{s}}=\pi / 6 \times \rho_{\mathrm{s}}\right. \\
\left.\quad\left(\text { with } \rho_{\mathrm{s}}=100 \mathrm{~kg} \mathrm{~m}^{-3}\right), d_{\mathrm{s}}=3\right]\end{array}$ \\
\hline EXP3 & $\begin{array}{l}V-D \text { parameters }\left(a_{\mathrm{s}}=8.996, b_{\mathrm{s}}=0.42\right. \\
\quad \text { from FERRIER } 1994)\end{array}$ \\
\hline EXP4 & Snow aggregation off \\
\hline EXP5 & Snow aggregation rate doubled \\
\hline EXP6 & $\lambda_{\mathrm{s} \_ \text {min }}=1 \mathrm{~m}^{-1}$ \\
\hline EXP7 & $\lambda_{\mathrm{s}_{\mathrm{m} \min }}=1,000 \mathrm{~m}^{-1}$ \\
\hline EXP8 & $N_{0 \mathrm{~s}}=f\left(-2.5^{\circ} \mathrm{C}\right)$ \\
\hline EXP9 & $N_{0 \mathrm{~s}}=f\left(-7.5^{\circ} \mathrm{C}\right)$ \\
\hline
\end{tabular}

Table 2

Parameters for snow in baseline MY2, in MKS units

\begin{tabular}{ll}
\hline Parameter & Value \\
\hline$a_{\mathrm{s}}$ & 11.72 \\
$b_{\mathrm{s}}$ & 0.41 \\
$c_{\mathrm{s}}$ & 0.1597 \\
$d_{\mathrm{s}}$ & 2.078 \\
$\lambda_{\mathrm{s} \_ \text {min }}$ & 500 \\
\hline
\end{tabular}

$20 \mathrm{~min}$ in the form of rain. A small amount of snow begins to arrive at the surface by $25 \mathrm{~min}$, even though the lowest level temperature is nearly $4{ }^{\circ} \mathrm{C}$. The snow precipitation rate at this time is very small. Nevertheless, there is a period of several hours (from approximately $60-340 \mathrm{~min}$ where there is a nonnegligible (i.e. $>0.1 \mathrm{~mm} \mathrm{~h}^{-1}$ ) amount of snow and rain precipitating at the surface simultaneously. During this period $T_{\mathrm{sfc}}$ drops from its initial value of $4{ }^{\circ} \mathrm{C}$ to nearly $0{ }^{\circ} \mathrm{C}$. We remark that the observed precipitation rates (Fig. 4a) fluctuate and with increasing irregularity at later times (after 0300 UTC) while the model precipitation rates are quite smooth. This is likely due to dynamical effects which are not captured by the $1 \mathrm{D}$ model.

Qualitatively, the CTR run realistically simulates the observed formation of a nearly isothermal layer near $0{ }^{\circ} \mathrm{C}$ below the melting level (500 $\mathrm{m}$ AGL) by $360 \mathrm{~min}$, corresponding to the VOC sounding at 0600 UTC (Fig. 3b) and the observed drop in surface temperature at VOT during this period (Fig. 4b). Also, the simulated precipitation rates correspond well to the observed rates of $1-2 \mathrm{~mm} \mathrm{~h}^{-1}$ at VOT during this 6-h period (Fig. 4a). The CTR simulation, therefore, has a sufficient degree of realism that we may conduct sensitivity experiments using the 1D model.

\subsection{Sensitivity to Assumptions and Parameters in $M Y 2$}

In the following experiments, the CTR simulation has been re-run, each with a change to a specific aspect of the microphysics scheme related to the snow category, but with the same initial sounding and initial and boundary condition snow field $\left(q_{\mathrm{s}}\right.$ and $\left.N_{\mathrm{s}}\right)$. The results for each run are summarized in Figs. 6, 7, $8,9,10,11,12$ with time-height plots of $q_{\mathrm{s}}, q_{\mathrm{r}}$, the differences in cooling rates due to melting between the given run and CTR, and time series of $R_{\text {liquid, }}$ $R_{\text {solid }}$, and $T_{\text {sfc }}$.

\subsubsection{One-Moment versus Two-Moment: EXP1}

The number of prognostic moments has been shown to have potential importance on snow growth (Milbrand et al., 2010). In the following test, the 

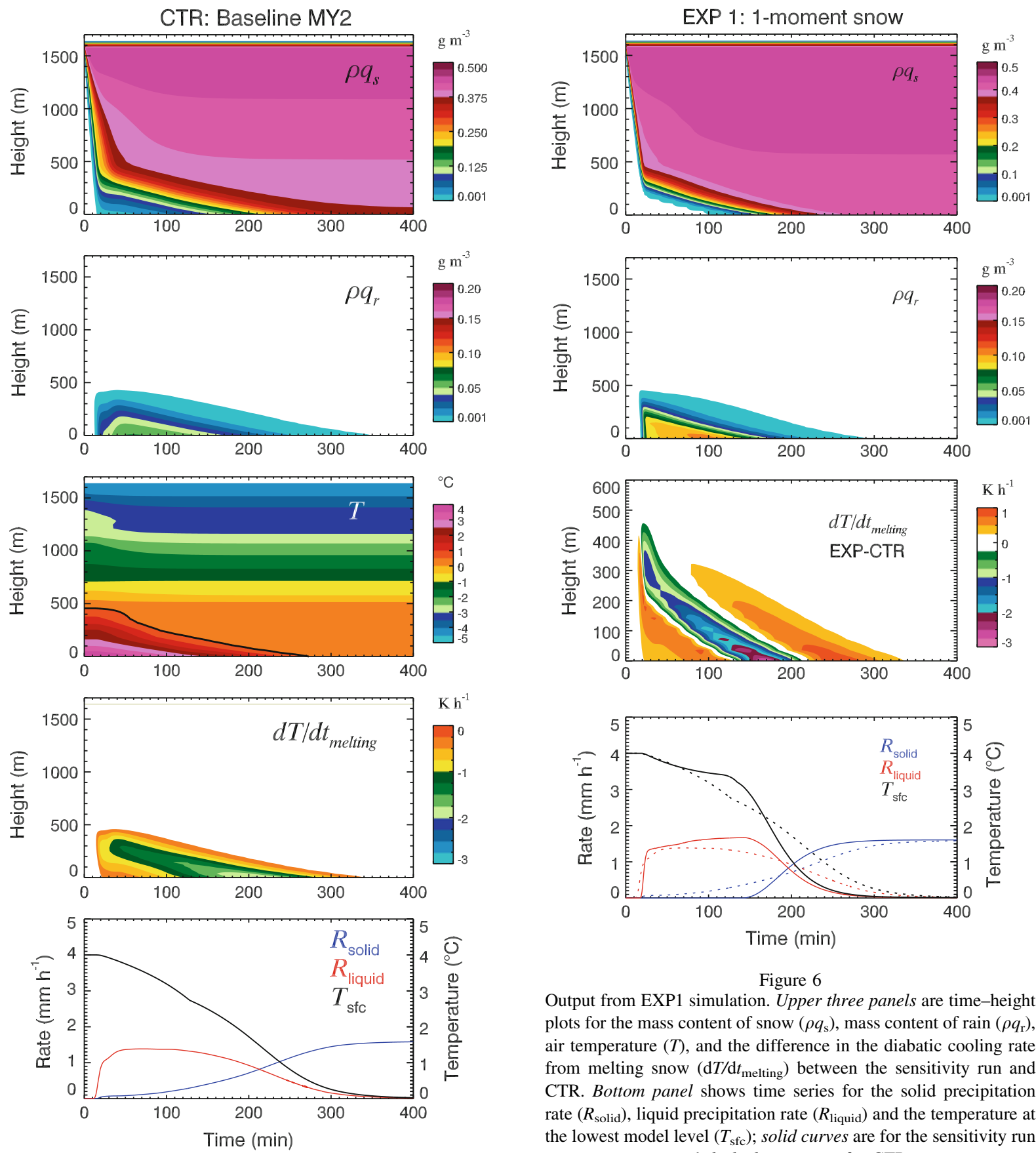

Figure 5

Output from CTR simulation. Upper four panels are time-height plots for the mass content of snow $\left(\rho q_{\mathrm{s}}\right)$, mass content of rain $\left(\rho q_{\mathrm{r}}\right)$, air temperature $(T)$ (line denotes the $0.5{ }^{\circ} \mathrm{C}$ isotherm), and the diabatic cooling rate from melting snow ( $\left.\mathrm{d} T / \mathrm{d} t_{\text {melting }}\right)$, respectively. Bottom panel shows time series for the solid precipitation rate ( $\left.R_{\text {solid }}\right)$, liquid precipitation rate $\left(R_{\text {liquid }}\right)$ and the temperature at the lowest model level $\left(T_{\text {sfc }}\right)$

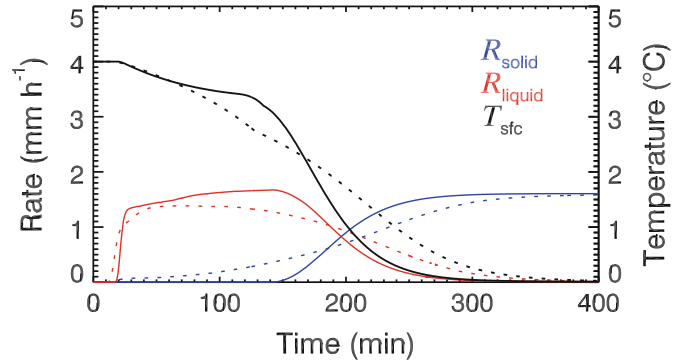

Figure 6

Output from EXP1 simulation. Upper three panels are time-height plots for the mass content of snow $\left(\rho q_{\mathrm{s}}\right)$, mass content of rain $\left(\rho q_{\mathrm{r}}\right)$, air temperature $(T)$, and the difference in the diabatic cooling rate from melting snow ( $\left.\mathrm{d} T / \mathrm{d} t_{\text {melting }}\right)$ between the sensitivity run and CTR. Bottom panel shows time series for the solid precipitation rate $\left(R_{\text {solid }}\right)$, liquid precipitation rate $\left(R_{\text {liquid }}\right)$ and the temperature at the lowest model level $\left(T_{\text {sfc }}\right)$; solid curves are for the sensitivity run and dashed curves are for CTR

snow category has been set to one-moment (prognostic $q_{\mathrm{s}}$ only) in the MY2 scheme. Due to the way that $N_{\mathrm{s}}$ is prescribed in the one-moment version, its initial highest-level value is also the same as in CTR. Whenever $q_{\mathrm{s}}>0$, the intercept parameter $N_{0 \mathrm{~s}}$ is 

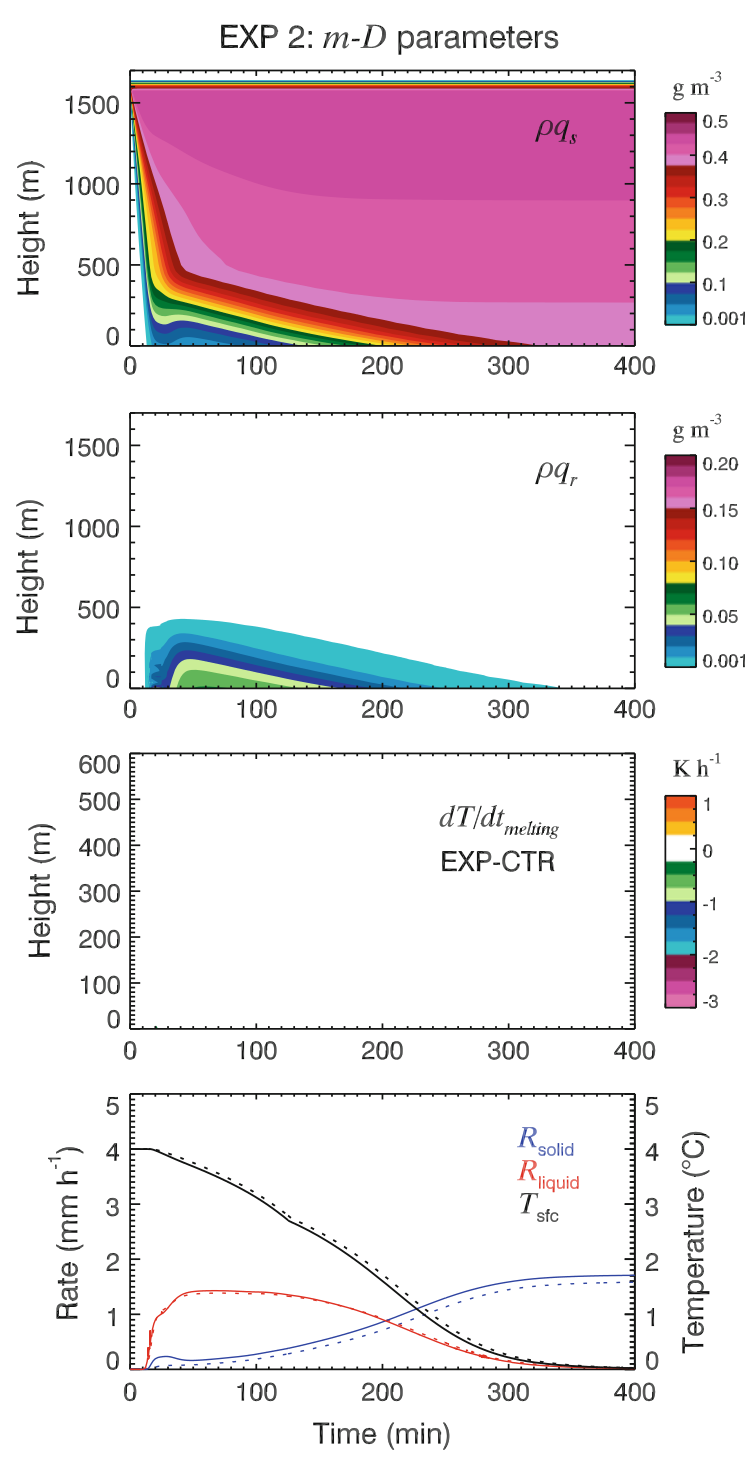

Figure 7

Output from EXP2 simulation. Upper three panels are time-height plots for the mass content of snow $\left(\rho q_{\mathrm{s}}\right)$, mass content of rain $\left(\rho q_{\mathrm{r}}\right)$, air temperature $(T)$, and the difference in the diabatic cooling rate from melting snow ( $\mathrm{d} T / \mathrm{d} t_{\text {melting }}$ ) between the sensitivity run and CTR. Bottom panel shows time series for the solid precipitation rate $\left(R_{\text {solid }}\right)$, liquid precipitation rate $\left(R_{\text {liquid }}\right)$ and the temperature at the lowest model level $\left(T_{\mathrm{sfc}}\right)$; solid curves are for the sensitivity run and dashed curves are for CTR

prescribed according to (C-3). Throughout the simulation, $N_{\mathrm{s}}$ is diagnosed according to (B-3).

The results from one-moment snow simulation (EXP1) are shown in Fig. 6. The differences in snow mass profiles are similar to that shown in 1D sedimentation-only experiments (MILBRANDT and
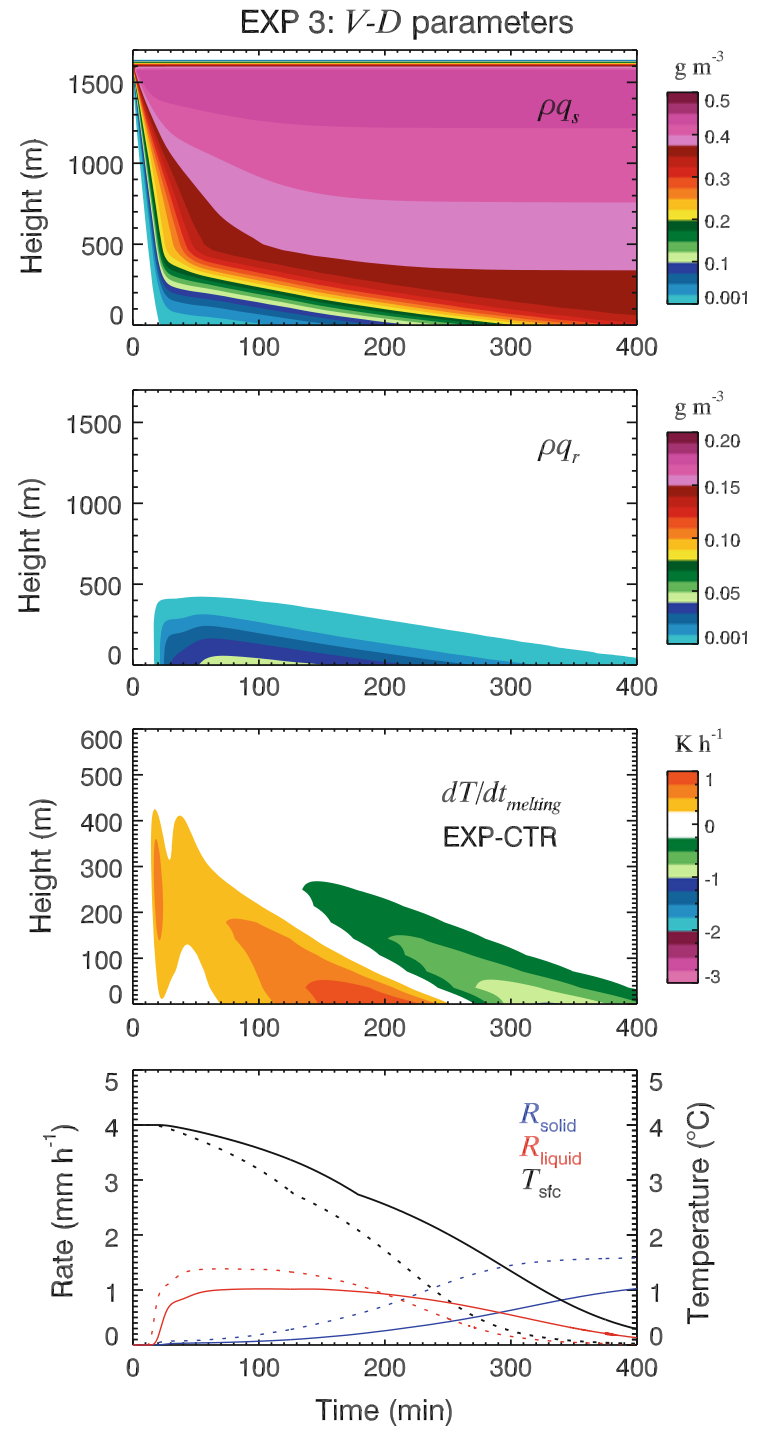

Figure 8

Output from EXP3 simulation. Upper three panels are time-height plots for the mass content of snow $\left(\rho q_{\mathrm{s}}\right)$, mass content of rain $\left(\rho q_{\mathrm{r}}\right)$, air temperature $(T)$, and the difference in the diabatic cooling rate from melting snow $\left(\mathrm{d} T / \mathrm{d} t_{\text {melting }}\right)$ between the sensitivity run and CTR. Bottom panel shows time series for the solid precipitation rate $\left(R_{\text {solid }}\right)$, liquid precipitation rate $\left(R_{\text {liquid }}\right)$ and the temperature at the lowest model level $\left(T_{\mathrm{sfc}}\right)$; solid curves are for the sensitivity run and dashed curves are for CTR

Yau 2005a; Milbrandt and McTaggart-Cowan 2010), where in one-moment the leading edge (lowest level with snow) falls slower but the mass becomes more evenly distributed throughout the column. This is because a two-moment (or higher) scheme is required to simulate the effect of gravitational 

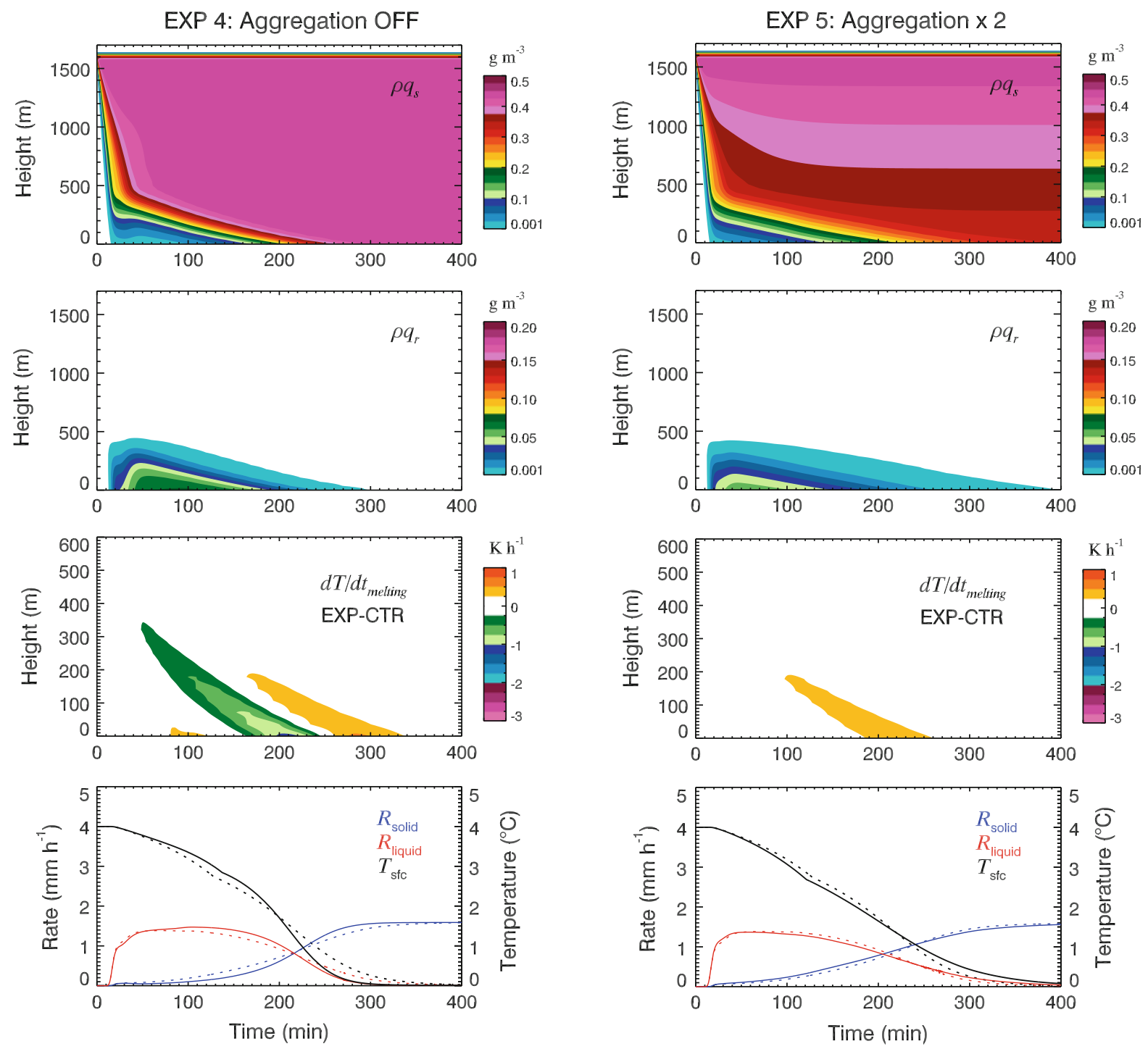

Figure 9

Output from EXP4 simulation. Upper three panels are time-height plots for the mass content of snow $\left(\rho q_{\mathrm{s}}\right)$, mass content of rain $\left(\rho q_{\mathrm{r}}\right)$, air temperature $(T)$, and the difference in the diabatic cooling rate from melting snow ( $\mathrm{d} T / \mathrm{d} t_{\text {melting }}$ ) between the sensitivity run and CTR. Bottom panel shows time series for the solid precipitation rate $\left(R_{\text {solid }}\right)$, liquid precipitation rate $\left(R_{\text {liquid }}\right)$ and the temperature at the lowest model level $\left(T_{\text {sfc }}\right)$; solid curves are for the sensitivity run and dashed curves are for CTR

size-sorting and the resulting redistribution of mass in the vertical. This results in a slight delay in the onset of surface precipitation in EXP1 (which arrives as rain) but then a slightly higher rate.

Except along the very leading edge of the falling snow, the cooling rate is stronger in EXP1 (shown by

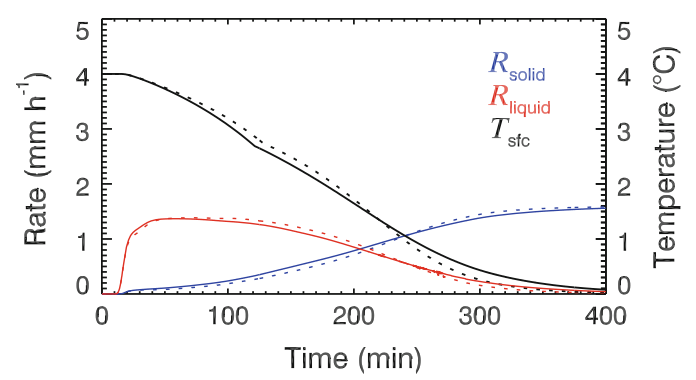

Figure 10

Output from EXP5 simulation. Upper three panels are time-height plots for the mass content of snow $\left(\rho q_{\mathrm{s}}\right)$, mass content of rain $\left(\rho q_{\mathrm{r}}\right)$, air temperature $(T)$, and the difference in the diabatic cooling rate from melting snow ( $\left.\mathrm{d} T / \mathrm{d} t_{\text {melting }}\right)$ between the sensitivity run and CTR. Bottom panel shows time series for the solid precipitation rate $\left(R_{\text {solid }}\right)$, liquid precipitation rate $\left(R_{\text {liquid }}\right)$ and the temperature at the lowest model level $\left(T_{\mathrm{sfc}}\right)$; solid curves are for the sensitivity run and dashed curves are for CTR

negative difference for EXP1-CTR). This, along with the differences in sedimentation, delays the transition from snow to rain at the surface, with the solid precipitation rate $R_{\text {solid }}$ now being zero until approximately $150 \mathrm{~min}$, rather than starting much earlier (approximately $20 \mathrm{~min}$ ) as in CTR. The diabatic 

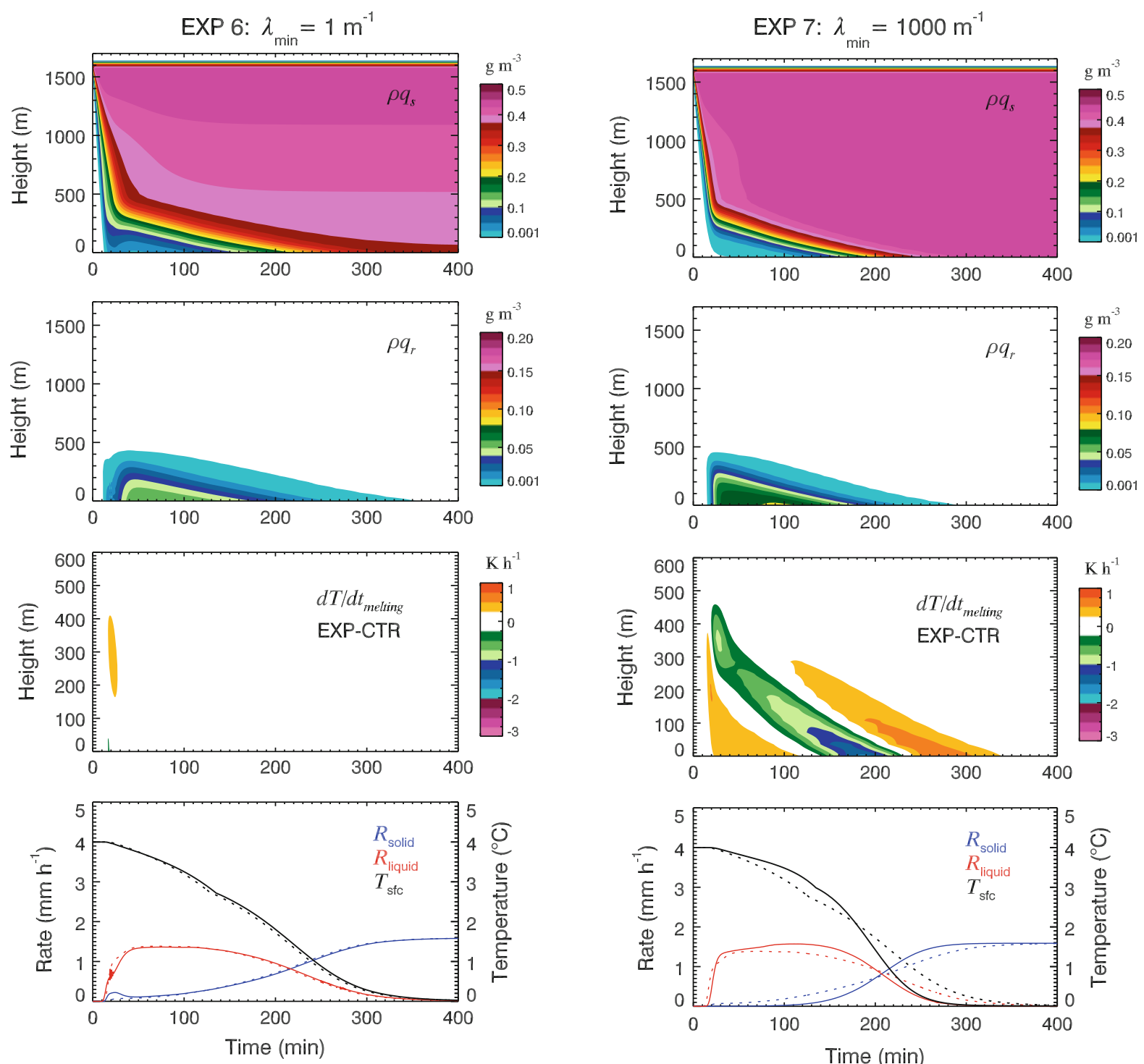

Figure 11

Output from EXP6 simulation. Upper three panels are time-height plots for the mass content of snow $\left(\rho q_{\mathrm{s}}\right)$, mass content of rain $\left(\rho q_{\mathrm{r}}\right)$, air temperature $(T)$, and the difference in the diabatic cooling rate from melting snow ( $\mathrm{d} T / \mathrm{d} t_{\text {melting }}$ ) between the sensitivity run and CTR. Bottom panel shows time series for the solid precipitation rate $\left(R_{\text {solid }}\right)$, liquid precipitation rate $\left(R_{\text {liquid }}\right)$ and the temperature at the lowest model level $\left(T_{\text {sfc }}\right)$; solid curves are for the sensitivity run and dashed curves are for CTR

cooling eventually penetrates to the surface, creating a nearly isothermal temperature profile below the melting layer, with the surface temperature approaching $0{ }^{\circ} \mathrm{C}$ after $220 \mathrm{~min}$, much sooner than in CTR. Even before this point, the rate of increase of $R_{\text {solid }}$ is notably greater.

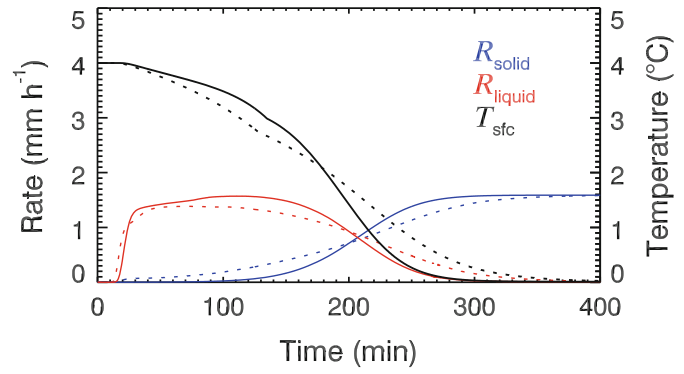

Figure 12

Output from EXP7 simulation. Upper three panels are time-height plots for the mass content of snow $\left(\rho q_{\mathrm{s}}\right)$, mass content of rain $\left(\rho q_{\mathrm{r}}\right)$, air temperature $(T)$, and the difference in the diabatic cooling rate from melting snow ( $\left.\mathrm{d} T / \mathrm{d} t_{\text {melting }}\right)$ between the sensitivity run and CTR. Bottom panel shows time series for the solid precipitation rate $\left(R_{\text {solid }}\right)$, liquid precipitation rate $\left(R_{\text {liquid }}\right)$ and the temperature at the lowest model level $\left(T_{\mathrm{sfc}}\right)$; solid curves are for the sensitivity run and dashed curves are for CTR

While the reduced time of the surface precipitation phase transition in EXP1 may appear to be more realistic in EXP1 than CTR, it must be recognized that results are due in part to how $N_{\mathrm{s}}$ (or $N_{0 \mathrm{~s}}$ ) is prescribed in the one-moment configuration. Different one-moment specification will lead to different 
prescribed size distributions and hence bulk fall speeds and melting rates. This is generally recognized as one of the major drawbacks of one-moment schemes (e.g. Ferrier 1994; Meyers et al., 1997; Milbrandt and McTaggart-Cowan 2010; Morrison and Milbrandt 2011). Nevertheless, the comparison illustrates the sensitivity of modeling this process to the number of prognostic moments for snow.

\subsubsection{Mass-Diameter Parameters: EXP2}

Hydrometeor categories in a BMS are generally assumed to have a particle mass-diameter $(m-D)$ relation of the form of (B-4). While work has been done using variable $m-D$ parameters diagnosed from the ambient conditions (e.g. LiN 2011), most schemes continue to use fixed parameters. In the original Milbrandt and YAU (2005b) scheme, snow was assumed to be spherical with a constant bulk density of $100 \mathrm{~kg} \mathrm{~m}^{-3}$, which implied $m-D$ parameters of $c_{\mathrm{s}}=(\pi / 6) 100 \mathrm{~kg} \mathrm{~m}^{-3}$ and $d_{\mathrm{s}}=3$. This is a common choice in many schemes (e.g. LiN and Colle 1983; Ferrier 1994; Morrison and Milbrandt 2005). In MY2, these parameters have been recently changed to $c_{\mathrm{s}}=0.1597$ and $d_{\mathrm{s}}=2.078$ (MKS units), similar to Thompson and Field (2008). See Thompson and Field (2008) and Milbrandt et al. (2012) for details and discussion. In EXP2, the original $m-D$ parameters for snow, implying a constant bulk density, were used.

While EXP2 (Fig. 7) has slightly more snow arriving at the surface early on, comparison to CTR (Fig. 5) indicates that the switch to the old $m-D$ parameters has little effect on the simulation of melting snow. Note, however, that there are other impacts to the more realistic $m-D$ parameters used in the baseline MY2 that involve snow growth processes (Thompson and Field 2008; Lin et al., 2009; MilbRANDT et al., 2012).

\subsubsection{Fall Velocity-Diameter Parameters: EXP3}

Bulk sedimentation velocities of the prognostic moments are computed using a terminal fall velocitydiameter $(V-D)$ relation of the form (B-5). Given the complexity of snow flake geometry and the difficulty in computing theoretical values, the $V-D$ parameters are generally determined empirically (e.g. LOCATELLI and
Hobis 1974; Mitchell 1996). The choice of parameters in the scheme is based on the assumed snow habit. Originally, MY2 scheme used the $V-D$ parameters given in FERRIER (1994). It was noted, however, that this set of parameters produces relatively slow falling snow which, due to longer time falling through supersaturated regions, can lead to excessive snow growth (MilBRANDT et al., 2010). The parameters where therefore changed to those corresponding to "graupellike snow of hexagonal type" (Locatelli and HobBs 1974) which produced faster falling snow and which corresponded to the new $m-D$ parameters.

The sensitivity of the phase transition to the snow fall velocity is examined by comparing CTR to EXP3, where we revert to the original (slower) $V-D$ parameters. The onset of surface precipitation is, or course, slightly delayed in EXP3 (Fig. 8), but the period of the phase transition is also greatly increase due to the slower falling snow having more time to melt to rain before arriving at the surface. Although the cooling rate is not much different, the melting occurs over a longer period thus the surface temperature drops much slower than in CTR. It should be noted that with the diabatic cooling, there are competing effects: while the slower sedimentation of snow means that the cooling period due to melting in a given layer is prolonged, the melting rate itself is reduced due to a reduced ventilation effect in the computation of the $q_{\mathrm{s}}$-tendency [due to a smaller $b_{\mathrm{s}}$ parameter; see MilBrandT and YAU (2005b) for details]. Overall, the comparison illustrates that the choice of snow $V-D$ parameters has a significant impact on the phase transition rate of the surface precipitation, with faster falling snow resulting in a shorter transition period.

\subsubsection{Treatment of Aggregation: EXP4 and EXP5}

One advantage of a two-moment snow scheme is the ability to parameterize aggregation. For this process the total number concentration, $N_{\mathrm{s}}$, is reduced without changing the total mass, $q_{\mathrm{s}}$ Hence, there is an increase the mean particle size and a decrease in $\lambda_{\mathrm{s}}$ [see (B-2)] and thus an increase in the bulk fall velocities and reduction in the melting rate. In MY2 this process is parameterized according to PASSARELLI (1978), which provides a sink term for $N_{\mathrm{s}}$. Despite the conceptual 
benefit of including aggregation, there are uncertainties in the parameterization, such as the value of the snow collection efficiency and the dispersion in fall speeds.

The sensitivity to the treatment of aggregation is examined in the following two experiments. In EXP4 aggregation is shut off entirely. The results (Fig. 9) indicate that the combined effects of reduced fall velocities and increased melting rates causes increased cooling due to melting compared to CTR (Fig. 5). Although the early reduction of surface temperature is slowed down as a result, by $120 \mathrm{~min}$ into the simulation, approximately the time an appreciable amount of snow reaches the surface, the rate that the surface temperature decrease becomes considerably faster compared to CTR and the entire phase transition period is much shorter, as indicated by the faster drop in $R_{\text {liquid }}$ and increase in $R_{\text {solid }}$.

On the other hand, with the aggregation rate doubled compared in EXP5 (Fig. 9), the differences compared to CTR (Fig. 5) are very small. There is a change in the $q_{\mathrm{s}}$ profiles consistent with the larger mean sizes and thus increased fall velocities, but the effect on the diabatic cooling rate and surface phase transition is negligible. The apparent lack of sensitivity to a large increase in aggregation yet sensitivity to shutting it off completely suggests that the baseline aggregation rate may be unrealistically high, given that the aggregation processes is bound to be important in such situations of phase transition. It must be recognized that since there is no dynamical feedback in this 1D model, so downdrafts cannot be induced by the diabatic cooling which would subsequently affect the surface conditions, only qualitative links to the diabatic changes and changes at the surface should be made. Further examination to improve the treatment of this process is warranted and modelers should be conscientious of this sensitivity.

\subsubsection{Minimum Allowable $\lambda_{s}$ : EXP6 and EXP7}

Two-moment schemes can realistically simulate the effect of gravitational size-sorting, whereby there is redistribution in the vertical of mean particle sizes, with large sizes appearing at lower altitudes (Milbrandt and Yau 2005a; Milbrandt and McTaggart-Cowan 2010). However, Heymsfield et al. (2008) pointed out that as aggregation occurs in nature, the disparity in sizes, and hence fall velocities, diminishes and thus size-sorting is eventually cut off. To account for this in the scheme, it was therefore recommended to impose a lower limit on the slope parameter $\left(\lambda_{\mathrm{s}}\right)$ of the snow size distribution. This is effectively identical to imposing a maximum allowable mean diameter. In MY2, a lower limit $\lambda_{\mathrm{s}}$ of $500 \mathrm{~m}^{-1}$ is used (equivalent to an upper limit mean diameter of $2 \mathrm{~mm}$ ). This is similar to the 600-700 $\mathrm{m}^{-1}$ recommended by Heymsfield et al. (2008) and found to be effective for controlling the upper range of values for the simulated snow-to-liquid ratio (MilbrandT et al., 2012). In EXP6 and EXP7, the sensitivity of this limit to the diabatic cooling and phase transition is tested.

The lower limit for $\lambda_{\mathrm{s}}$ is essentially removed in EXP6 (the limit is set to $1 \mathrm{~m}^{-1}$, which is never reached). Removing this limit had very little effect for this case (Fig. 11) compared to CTR (Fig. 5). This is because the lowest value of $\lambda_{\mathrm{s}}$ in CTR is usually above $500 \mathrm{~m}^{-1}$ anyway. However, for situations with larger mean snow diameters and thus with $\lambda_{\mathrm{s}}$ smaller than $500 \mathrm{~m}^{-1}$, the limit in the baseline configuration would likely have a more noticeable effect on the phase transition.

In EXP7 (Fig. 12), the limit is increased to $1,000 \mathrm{~m}^{-1}$ (corresponding to maximum mean diameter of $1 \mathrm{~mm}$ ). Imposing this more stringent limit has the effect of increasing the diabatic cooling rate, delaying the onset of snow arrival at the surface, and reducing the phase transition period. This is due to the snow in the melting layer having smaller mean sizes (not shown) in this region compared to CTR and thus having slower fall velocities and faster melting rates. Note that this was very similar to EXP4 where shutting off aggregation similar changes to the snow size distributions, though for a different reason, and hence similar results. Thus, given that two-moment sedimentation always ${ }^{3}$ tends the profiles towards larger mean sizes at lower altitudes, the specific value of the minimum allowable slope parameter can have

\footnotetext{
3 While this is true, it was shown (MilBRANDT 2005a) that increasing the value of the shape parameter $\mu$ in (B-2) can effectively reduce the extent to which this size-sorting process is overdone.
} 
a notable impact on the simulated timing and duration of the phase transition period with a two-moment BMS, depending on how aggregation is treated.

\section{Discussion}

\subsection{Implication of Results}

The sensitivity tests presented above clearly indicate that the timing and duration of the precipitation phase transition from snow to rain when the melting level is near the surface can be sensitive to details in the parameterization of snow in the microphysics scheme. An implication from these simple idealized tests is that a high-resolution NWP model using a similar BMS may have a similar sensitivity and will thus be subject to similar uncertainties in terms of forecasting phase transitions. One approach to treat this problem is to attempt to ensure that the scheme uses the best possible choice of parameters. There are various ways to attempt to achieve this.

For some processes, the parametric equations can be calibrated to closely reproduce the results from a very detailed model, taken to represent the truth, or in some cases from an analytic solution. For example, WestвRоoк et al. (2008) made detailed calculations of the diffusional growth of realistic snow crystals and provided useful correction factors for bulk schemes using the parametric equation from the electrostatic change analogy. For sedimentation, Milbrandt and McTaggart-Cowan (2010) computed errors from one-, two-, and three-moment bulk schemes and provided means of minimizing the errors based on the choice of sedimenting moments.

For several processes, however, some degree of tuning is unavoidably necessary given our lack of complete understanding of the physical process or the need to make simplifications due to computational cost. This cannot be done using results from a highly simplified model configuration, such as with a 1D kinematic model as used in this study, but rather should be performed using full model simulations and good observational data. The danger of tuning a model based on a single case, however, is that configurations that work well for one case may not work well in general. A numerical model should always be regarded, to some extent, as a system of compensating approximations and errors. This means that improvement to the treatment of any single process may sometimes degrade the results overall. Therefore, due to inherent uncertainties calibration of a microphysics scheme, or any other aspect of a model, has intrinsic limitations.

Given that a perfect microphysics scheme (and a perfect model in general) is inherently impossible to construct, the alternative in terms of improving forecasting is to work within the uncertainties. One approach is to use an ensemble of high-resolution model forecasts. This was examined in the 2011 Hazardous Weather Testbed Spring Experiment, where a 50-member ensemble was run using a mesoscale model with a 4-km horizontal grid spacing (Kong et al. 2011). For one set of members, each member was identical except for the choice of microphysics scheme. An extension of this would be to include a set of members using the same scheme but with each member having a different configuration of parameter values, within realistic ranges. Results could provide a probabilistic forecast based on the range of uncertainty within the scheme. While potentially useful, operational use of this approach will likely be prohibitive in terms of computational cost for several years.

\subsection{Potential Application of $1 D$ Model as a Forecasters' Tool}

For forecasting aspects such as precipitation phase transitions, understanding of and accounting for the uncertainty in the microphysics can be crucial. Although a high-resolution ensemble system is currently unfeasible operationally, it may be possible to make use of a 1D modeling system to account for uncertainty, given that such a system is extremely economical and it is simple to run a large number of tests. At least two potential applications for such a model as a tool for operational forecasters are conceivable.

First, a type of ensemble system could be set up using the 1D model. Brimelow et al. (2006) a describe a system with a 1D cloud model coupled to a detailed hail growth model which was interfaced with an operational NWP model that provided the initial 
temperature and humidity profiles at various locations. An ensemble of 1D simulations was run with perturbed surface temperatures and dew point temperatures, thereby accounting for a range possible peak updraft velocities in the cloud model, providing a probabilistic forecast of the maximum possible hail sizes. Similarly, the modeling system described in this study could be used, with initial conditions (e.g. snow field, temperature and humidity profile) supplied from a high-resolution deterministic model and the 1D model used to produce an ensemble of simulations, where the individual members are run use different microphysics parameter values.

Second, the 1D model could be set up such that a forecaster could readily perform a variety of "what if" experiments, varying not only aspects of the microphysics scheme, such as was described in the previous section, but also the initial and/or boundary conditions. For example, in the CTR simulation, the snow field at the upper level was prescribed based on the observed radar reflectivity of $25 \mathrm{dBZ}$ at an elevation whose temperature was $-7.5{ }^{\circ} \mathrm{C}$, which was used to estimate the intercept parameter $\left(N_{0 \mathrm{~s}}\right)$ based on the THOMPSON et al. (2004) temperature relation ("Appendix 3"). A forecaster could examine the sensitivity of specifying the snow field with the observed reflectivity but at a slightly colder or warmer temperature, which would change how $N_{0 \mathrm{~s}}$, and hence $N_{\mathrm{s}}$, is initialized. Figures 13 and 14 summarize the results from simulations EXP8 and EXP9 where the temperature used to prescribe the upper level $N_{0 \mathrm{~s}}$ was changed to -7.5 and $-2.5{ }^{\circ} \mathrm{C}$, respectively. Using the colder temperature (EXP8; Fig. 13), the initial $N_{0 \mathrm{~s}}\left(\right.$ and $N_{\mathrm{s}}$ ) is larger than in CTR; with the same prescribed reflectivity, this gives a greater upper-level $q_{\mathrm{s}}$ values (see "Appendix 3 "). With the increase snow mass flux, the precipitation rates are both larger than in CTR and the transition period is slightly shorter. The case is reversed for EXP9 (Fig. 14) using a warmer temperature to prescribe $N_{0 s}$. Similar experiments could be performed by varying the reflectivity, the initial temperature and humidity profile, or even imposing a vertical velocity field.

A single simulation such as those presented takes only a few seconds to run on a single-processor desktop computer, thus a forecaster could easily and quickly perform a large number of runs to test hypothetical scenarios for a given forecast situation. Forecasters at Environment Canada are currently exploring the possibility of using this 1D kinematic modeling system described here as potential tool to conduct such tests during real-time operational situations where the high-resolution NWP model are expected to be subject to large errors and uncertainties.

\section{Conclusion}

A simple 1D kinematic model coupled to a detailed two-moment microphysics scheme was used to simulate the surface precipitation phase transition, based on a case that occurred during the Vancouver 2010 Winter Olympics where diabatic cooling due to melting is hypothesized to have contributed to an observed precipitation phase change and low-level flow reversal. A series of numerical tests was conducted to examine the sensitivity to specific microphysics parameters related to snow, including those affecting the representation of the particle size distribution, the mass-diameter relation, the terminal fall velocity, and the treatment of aggregation. The results indicate that when the melting level is relatively close to the ground, as is often the case in mountainous coastal regions, the predicted timing and duration of the precipitation phase change can be quite sensitive to the parameterization details of specific microphysical processes. Users of high-resolution model output should therefore be conscientious of these inherent uncertainties for such situations.

For interpreting the results in terms of the expected impacts in a NWP model, the simple 1D framework has limitations. Besides not having horizontal flow, it is purely kinematic and thus the vertical motion field does not respond to diabatic forcing. Nevertheless, there are some distinct advantages of the kinematic framework. Despite the simplicity of the driving model, the microphysics scheme used was identical to that used in an operational high-resolution NWP model. The simplicity of the 1D model, however, allows one to conduct sensitivity experiments that are easy to interpret, with changes in the results being entirely attributable to the change in the microphysics, without the 

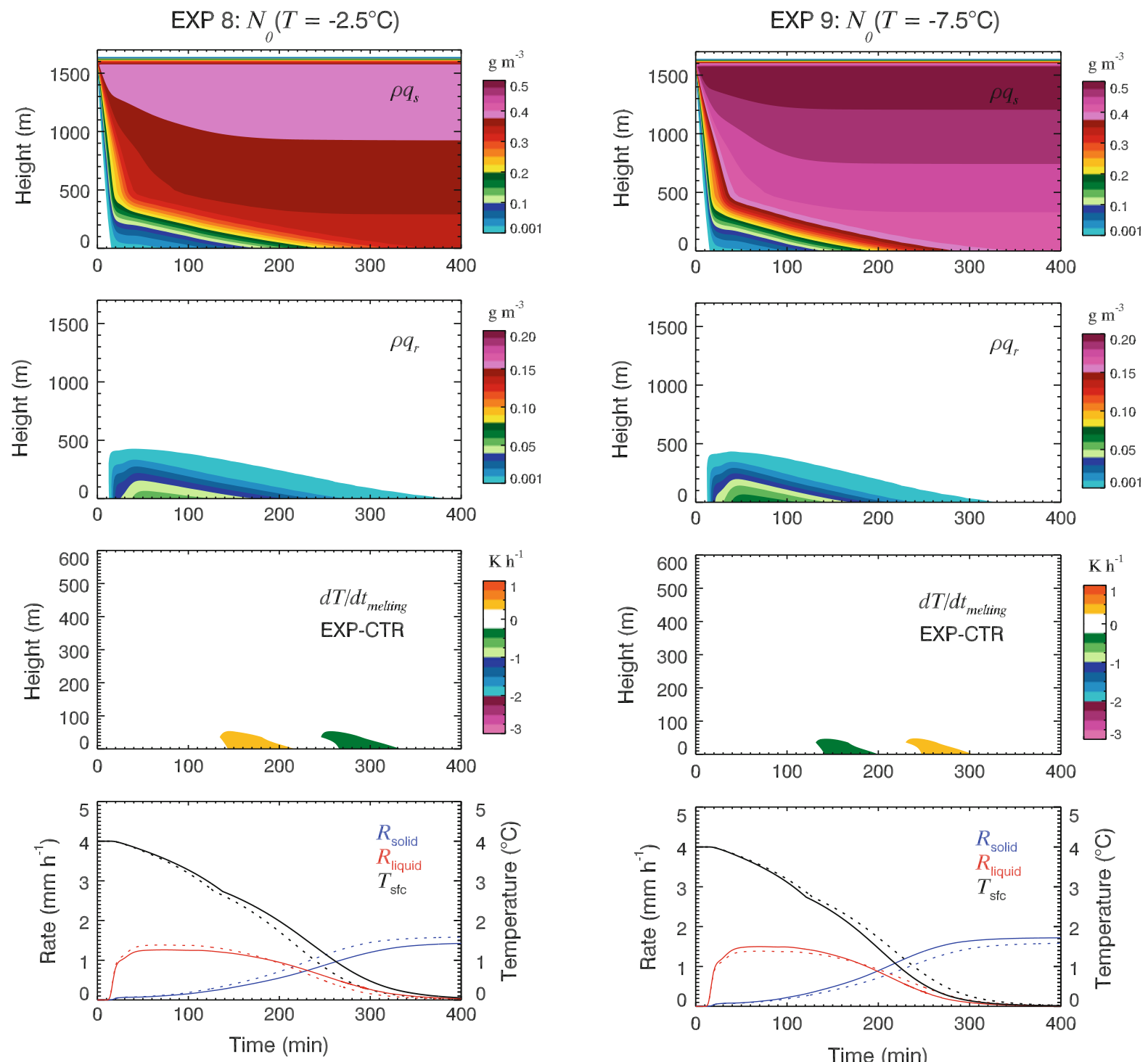

Figure 13

Output from EXP8 simulation. Upper three panels are time-height plots for the mass content of snow $\left(\rho q_{\mathrm{s}}\right)$, mass content of rain $\left(\rho q_{\mathrm{r}}\right)$, air temperature $(T)$, and the difference in the diabatic cooling rate from melting snow ( $\left.\mathrm{d} T / \mathrm{d} t_{\text {melting }}\right)$ between the sensitivity run and CTR. Bottom panel shows time series for the solid precipitation rate $\left(R_{\text {solid }}\right)$, liquid precipitation rate $\left(R_{\text {liquid }}\right)$ and the temperature at the lowest model level $\left(T_{\mathrm{sfc}}\right)$; solid curves are for the sensitivity run and dashed curves are for CTR

complication of feedback from the dynamical model. A similar sensitivity to the microphysics parameterizations illustrated by the results of the 1D simulations may be expected to exist in an operational model using the same type of scheme. On the other hand, feedbacks in a full dynamical model

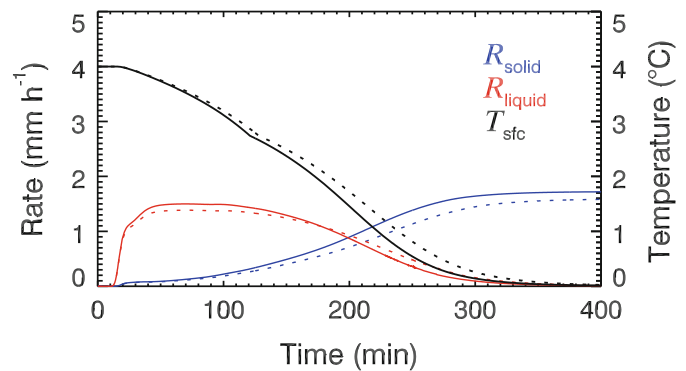

Figure 14

Output from EXP9 simulation. Upper three panels are time-height plots for the mass content of snow $\left(\rho q_{\mathrm{s}}\right)$, mass content of rain $\left(\rho q_{\mathrm{r}}\right)$, air temperature $(T)$, and the difference in the diabatic cooling rate from melting snow $\left(\mathrm{d} T / \mathrm{d} t_{\text {melting }}\right)$ between the sensitivity run and CTR. Bottom panel shows time series for the solid precipitation rate $\left(R_{\text {solid }}\right)$, liquid precipitation rate $\left(R_{\text {liquid }}\right)$ and the temperature at the lowest model level $\left(T_{\text {sfc }}\right)$; solid curves are for the sensitivity run and dashed curves are for CTR

make change the sensitivity to the microphysics. Nevertheless, users should at least be aware of the types of uncertainties.

Despite the range of results, all of the simulations presented in this study exhibited relatively long phase 
transition periods, where both the rain and snow precipitation rates were non-negligible. This is long-lived mixed-phase period is unrealistic and is due primarily to a limitation in the MY2 scheme, inherent in most BMSs used in NWP models, which pertains to the treatment of melting. In the model, when snow begins to melt, the portion of mass that melts in one time step goes directly to rain. The rain and the remaining snow, which is assumed to be dry, continue to as the snow mass gradually decreases with melting. In nature, a snowflake does not shed drops as it melts, unlike melting graupel or hail, but rather it retains the liquid portion from the melted mass, and sediments faster as the liquid-to-solid ratio increases, until it reaches the point where it collapses into a single drop (KNIGHT 1979). The current scheme lacks the means of accounting for partially melted snow and will thus systematically overestimate the mixed-phase transition period, regardless of other parameter settings.

In order to remedy this, some modelers have taken the approach to incorporate additional mixedphase hydrometeor categories (e.g. THÉRIAULT and Stewart 2010). However, this adds computational cost to the model. To account for partial melting without additional prognostic variables, the MY2 scheme has been recently modified to estimate the liquid fraction of partially melted snow and adjust the fall velocities of both snow and rain accordingly, thereby simulating a more realistic transition from snow to rain. Preliminary tests indicate that this approach leads to a more realistic simulation of the phase transition period. Results with this modification and its affects in more detailed model configurations (2D and 3D dynamical models) will be reported in a future paper.

\section{Acknowledgments}

The observational data used in this study was obtained during the Science of Nowcasting Winter Weather for Vancouver 2010 (SNOW-V10) field campaign. We gratefully acknowledge the constructive comments from two anonymous reviewers.

Open Access This article is distributed under the terms of the Creative Commons Attribution License which permits any use, distribution, and reproduction in any medium, provided the original author(s) and the source are credited.

\section{Appendix 1: Description of the 1D Kinematic Model}

The 1D model system consists of is a simple kinematic cloud model coupled to a bulk microphysics scheme (described in "Appendix 2"), with the option for a prescribed, time-varying vertical motion profile. The model is initialized with a single sounding by reading the temperature $(T)$, dew point $\left(T_{\mathrm{d}}\right)$, height $(z)$ and pressure $(p)$ from an input file at various levels. The vertical axis is discretized into $n k$ (user specified) evenly-spaced model levels to which $T, T_{\mathrm{d}}$ and $p$ are then interpolated using a cubic spline. The air density $\rho$ is computed at each level by the ideal gas law. The initial water vapor mixing ratio, $q_{\mathrm{v}}$, is then computed from $T_{\mathrm{d}}$ at each level and the prognostic hydrometeor variables ("Appendix 2") are initialized to zero or to values specified by the user.

A vertical motion profile is prescribed to follow an analytic function, a half sine wave with values of zero at the upper and lower boundaries and a maximum value, $w_{\max }$, in the middle:

$$
w(k)=w_{\max } \sin \pi \frac{z(k)-z(n k)}{H-z(1)},
$$

where $k$ is the level index (increasing downward, such that $k=1$ is the uppermost level) and $H$ is the height of the vertical motion profile. The $w$ profile can be specified to evolve in time during the integration. The corresponding profiles of divergence and compressibility are prescribed accordingly.

At each time step, the model solves the mass divergence form of the continuity equation:

$$
\frac{\partial\left(\rho \Psi_{x}\right)}{\partial t}+\vec{\nabla} \cdot\left(\rho \Psi_{x} \vec{U}\right)=S_{1}
$$

for each prognostic hydrometeor variable $\Psi_{x}$, where $\Psi$ is either $q$ or $N^{\prime}$, the hydrometeor mixing ratio or total number mixing ratio, respectively, with $x$ indicating the hydrometeor category (see "Appendix 2"), $\vec{U}$ is the velocity vector (equal to $w$ in 1D), and 


$$
S_{x}^{\prime}=\left.\frac{\partial\left(\rho \Psi_{x}\right)}{\partial t}\right|_{\text {microphysics }}
$$

is the forcing from the microphysics. The change in water vapour mixing ratio, $q_{\mathrm{v}}$, is also solved from (A-2). The anelastic approximation is made,

$$
\rho=\rho_{0}(z),
$$

where $\rho_{0}(z)$ is the constant basic state air density, allowing (A-2) to be expressed as,

$$
\frac{\partial \Psi_{x}}{\partial t}+w \frac{\partial \Psi_{x}}{\partial z}+\Psi_{x} \frac{\partial w}{\partial z}+\Psi_{x} w \frac{1}{\rho_{0}} \frac{\partial \rho_{0}}{\partial z}=\frac{S_{x}^{\prime}}{\rho_{0}},
$$

where the second, third and forth term on the LHS represent advection, divergence and compressibility, respectively. Bringing the advection and compressibility terms over to the RHS and defining

$$
S_{x}=\frac{S_{x}^{\prime}}{\rho_{0}}=\left.\frac{\partial \Psi_{x}}{\partial t}\right|_{\text {microphysics }},
$$

which is the tendency due to growth/decay processes and sedimentation from the microphysics scheme, gives

$$
\frac{\partial \Psi_{x}}{\partial t}+w \frac{\partial \Psi_{x}}{\partial z}=-\Psi_{x} \frac{\partial w}{\partial z}-\Psi_{x} w \frac{\partial \ln \rho_{0}}{\partial z}+S_{x} .
$$

A forward-in-time/backward-in-space Eulerian advection scheme is used. The divergence term can be determined analytically (provided that $w$ is an analytic function); the compressibility term is solved by centered-in-space differencing. Note that in the cloud model, the hydrometeor number concentration variables, $N_{x}^{\prime}$, are in mixing ratio units $\left(\# \mathrm{~kg}^{-1}\right)$, which is necessary for conservation, but within the microphysics scheme they are converted to density units $\left(\# \mathrm{~m}^{-3}\right)$.

For temperature, $T$ is advected at each time step and then the tendency due to adiabatic ascent/decent is added:

$$
T_{\mathrm{k}}^{* \tau+1}=T_{\mathrm{k}}^{\tau}+\Delta t \Gamma_{\mathrm{d}} w_{\mathrm{k}},
$$

where $\tau$ is the model time step, $\Gamma_{\mathrm{d}}$ is the dry adiabatic lapse rate, and “* $*^{\tau+1}$ " denotes the intermediate time level after advection but before the microphysics. The temperature change due to the microphysics (latent heating/cooling) is then added to obtain $N_{\mathrm{k}}^{\tau+1}$. Following the anelastic assumption, the air density, $\rho$, is not recomputed at the end of the time step.
Although $w$ is zero at the top and bottom boundaries, the values of $q_{\mathrm{v}}$ and $T$ can change at the boundaries due to the divergence term ( $q_{\mathrm{v}}$ only) and microphysics tendencies. Temperature at the bottom level is allowed to change according to microphysics feedback (i.e. evaporative cooling), but never changes at the uppermost level. The bottom boundary condition for $q_{\mathrm{v}}$ is potentially important for some tests. Allowing it to vary freely means that $q_{\mathrm{v}}$ can decrease significantly depending on the divergence profile. For example, a half sine wave $w$ profile implies a corresponding half cosine wave divergence profile, with divergence in the bottom half of the domain and convergence in the top half. Thus, lowlevel divergence of water vapor and subsequent upward advection of dry air from lower-levels can cause evaporation of the cloud from below, which may be unwanted for certain types of tests. If this is a problem, one approach to treat this is to enforce the lower boundary condition $q_{\mathrm{v}}^{\tau+1}=q_{\mathrm{v}}(\tau=0)$ at the end of the time step, effectively holding the surface moisture constant. The implicit assumption is that whenever low-level water vapor is depleted due to upward advection (i.e. low-level divergence), water vapor is added back to those levels (due to implicit advected from the side, for example). Consequently, the cloud is never evaporated from below and there is a constant supply of new vapor (note, this approach was not used in this study).

\section{Appendix 2: Overview of the Microphysics Scheme}

The BMS used in this study was originally described in Milbrandt and Yau (2005a, b) and references therein. Recent modifications to the snow category are described in MiLBRANDT et al. (2012); other changes are summarized in MilbRANDT et al. (2010). The full version is a 3-moment scheme with prognostic equations for the mass mixing ratio, total number concentration, and radar reflectivity $\left(q_{x}, N_{x}\right.$, and $Z_{x}$, respectively) for $x=c, r, i, s, g, h$ corresponding to the six hydrometeor categories: cloud (liquid droplets), rain (precipitating drops), ice (pristine crystals), snow (large crystals/ aggregates), graupel (medium-density rimed ice), and hail (high density rimed ice and/or frozen drops). The particle size distribution (PSD) of each category $x$ is represented by a complete gamma function of the form: 


$$
N_{x}(D)=N_{0 x} D^{\mu_{x}} \mathrm{e}^{-\lambda_{x} D},
$$

where $N_{0 x}, \lambda_{x}$, and $\mu_{x}$ are the intercept, slope, and shape parameters, respectively, and $D$ is the particle diameter. The two-moment version, with prognostic equations for $q_{x}$ and $N_{x}$ only, has options for either fixed or diagnostically determined variable $\mu_{x}$.

In this study, only the two-moment fixed- $\mu_{x}$ version (MY2) is used, with $\mu_{x}=0$ for $x=i, r, s, g, h$ (implying inverse-exponential PSDs) and $\mu_{x}=3$ for cloud droplets. The parameters $N_{0 x}$ and $\lambda_{x}$ can be computed from the prognostic variables, $q_{x}$ and $N_{x}$, by:

$$
\lambda_{x}=\left[\frac{c_{x} N_{x} \Gamma\left(\mu_{x}+4\right)}{q_{x} \Gamma\left(\mu_{x}+1\right)}\right]^{\frac{1}{d_{x}}}
$$

and

$$
N_{0 x}=\frac{N_{x} \lambda_{x}^{\mu_{x}+1}}{\Gamma\left(\mu_{x}+1\right)},
$$

with a mass-diameter $(m-D)$ relation for each particle given by,

$$
m_{x}(D)=c_{x} D^{d_{x}},
$$

and $\Gamma$ is the complete gamma function. All particles are assumed to be spherical and, except for snow, have constant bulk densities, $\rho_{x}$. Thus, $c_{x}=\left(\pi / 6 \rho_{x}\right)$ and $d_{x}=3$. For snow, the $m-D$ parameters themselves imply a non-constant bulk density, which is approximately inversely proportional to $D$ (see MiLBRANDT et al., 2012, for details).

The moment-weighted bulk fall velocities for each of the prognostic moments are computed using an assumed power-law velocity-diameter $(V-D)$ relation,

$$
V_{x}(D)=\gamma a_{x} D^{b_{x}}
$$

where $\gamma=\left(\rho_{0} / \rho\right)^{0.5}$ is the air density correction factor, with $\rho$ and $\rho_{0}$ equal to the air density aloft and at the surface, respectively, and $a_{x}$ and $b_{x}$ are constant parameters, appropriate for each hydrometeor category.

\section{Appendix 3: Calculations of Initial and Boundary Condition Snow Field}

In order to prescribe a constant snow field falling from above for the simulations in this study, constant values of the prognostic variables $q_{\mathrm{s}}$ and $N_{\mathrm{s}}$ are specified at the uppermost model level at each time step. The values of these variables can either be chosen directly or computed based on other variables and appropriate closure equations to solve for $q_{\mathrm{s}}$ and $N_{\mathrm{s}}$. Realistic conditions for this 13-14 February 2010 case are desired for this study; therefore available observations were used. The model top was specified to be 1,600 m AGL. The observed radar reflectivity $Z$ at this level, at the location of the VOT station at the initial model time (0000 UTC February 14), was approximately $25 \mathrm{dBZ}$ (Fig. 2). The air temperature at this level, according to the nearby sounding at VOC was approximately $-5{ }^{\circ} \mathrm{C}$ (Fig. 3). For simplicity, it is assumed that the hydrometeor mass content there was entirely snow. Thus, we take the observed $Z$ to be equal to the equivalent reflectivity of snow, $Z_{\mathrm{es}}$, from which the reflectivity factor for snow, $Z_{\mathrm{s}}$, can be computed using:

$$
Z_{\mathrm{es}}=\frac{|K|_{\mathrm{i}}^{2}}{|K|_{\mathrm{w}}^{2}}\left(\frac{\rho_{\mathrm{w}}}{\rho_{\mathrm{i}}}\right)^{2}\left(\frac{c_{\mathrm{s}}}{c_{\mathrm{r}}}\right)^{2} Z_{\mathrm{s}},
$$

where $|K|_{\mathrm{i}}^{2} /|K|_{\mathrm{w}}^{2}=0.176 / 0.930=0.189$ is the ratio of the dielectric constants for ice and water (SMITH 1984), $\left(\rho_{\mathrm{w}} / \rho_{\mathrm{i}}\right)^{2}=\left(1,000 \mathrm{~kg} \mathrm{~m}^{-3} / 917 \mathrm{~kg} \mathrm{~m}^{-3}\right)^{2}=1.189$ is the square of the ratio of the densities of water and ice, $c_{\mathrm{r}}=(\pi / 6) \rho_{\mathrm{w}}$ (where $\rho_{\mathrm{w}}$ is the density of water), $c_{\mathrm{s}}$ is the coefficient of the mass-diameter relation (see Table 2). $Z_{\mathrm{s}}$ is equal to the sixth moment of the size distribution and, using (B-1) and (B-3) along with the definition of a moment, can be shown to be equal to:

$$
Z_{s}=\frac{\Gamma\left(7+\mu_{s}\right) \Gamma\left(1+\mu_{s}\right)}{\Gamma\left(4+\mu_{s}\right)^{2}} \cdot \frac{\left(\rho q_{s}\right)^{2}}{c_{s}^{2} N_{s}} .
$$

We use the following approximation from Thompson (2004) to estimate the value of the $N_{O \mathrm{~s}}$ from the observed temperature, $T$ :

$$
\begin{aligned}
& N_{0 s}=\min \left\{2 \times 10^{8}, 2\right. \\
& \left.\times 10^{6} x \exp [-0.12 \cdot \min (-0.001, T-273.15)]\right\} .
\end{aligned}
$$

Using $N_{O s}\left(-5^{\circ} \mathrm{C}\right)$ from $(\mathrm{C}-3)$ and the value of $Z_{\mathrm{s}}$ from (C-1), along with an assumed shape parameter $\mu_{\mathrm{s}}=0$, equations (B-2), (B-3), and (C-2) form a system of equations that can be used to solve for $q_{\mathrm{s}}$ and $N_{\mathrm{s}}$.

For CTR and EXP1 through EXP7, the initial and upper boundary snow field variables were thus 
prescribed to be $q_{\mathrm{s}}=0.45 \mathrm{~g} \mathrm{~kg}^{-1}$ and $N_{\mathrm{s}}=$ $1,315 \mathrm{~m}^{-3}$ (note, at this level $\rho=1.00 \mathrm{~kg} \mathrm{~m}^{-3}$, so the number mixing ratio $N_{\mathrm{s}}^{\prime}=1,315 \mathrm{~kg}^{-1}$.) For EXP8, with $T=-2.5{ }^{\circ} \mathrm{C}$, the values were computed to be $0.40 \mathrm{~g} \mathrm{~kg}^{-1}$ and $N_{\mathrm{s}}=2,447 \mathrm{~m}^{-3}$; for EXP9, with $T=-7^{\circ} \mathrm{C}$, the values were $0.50 \mathrm{~g} \mathrm{~kg}^{-1}$ and $N_{\mathrm{s}}=3,944 \mathrm{~m}^{-3}$.

\section{REFERENCES}

Brimelow, J. C., G. W. Reuter, R. Goodson, T. W. Krauss, 2006: Spatial forecasts of maximum hail size using prognostic model soundings and HAILCAST. Wea. Forecasting, 21, 206-219.

FERRIER, B. S, 1994: A double-moment multiple-phase four-class bulk ice scheme. Part I: Description. J. Atmos. Sci., 51, 249-280.

Gultepe, I., G.A. Isaac, P. Joe, P.A. Kucera, J. Thériault, and T. FISICO, 2012: Roundhouse (RND) Mountain Top research site: Measurements and uncertainties for winter alpine weather conditions, J. Pure Appl. Geophy., In press.

Heymsfield, A. J., P. Field, and A. Bansemer, 2008: Exponential size distributions for snow. J. Atmos. Sci., 65, 4017-4031.

Isaac, G.A., P.I. Joe, J. Mailhot, M. Bailey S. Bélair, F.S. Boudala, M. Brugman, E. Campos, R. L. Carpenter JR., R.W. Crawford, S. G. Cober, B. Denis, C. Doyle, H.D. Reeves, I. Gultepe, T. Haiden, I. Heckman, L.X. Huang, J.A. Milbrandt, R. Mo, R.M. Rasmussen, T. Smith, R.E. Stewart, D. WANG and L.J. WiLson, 2012: Science of Nowcasting Olympic Weather for Vancouver 2010 (SNOW-V10): A World Weather Research Programme project. J. Pure Appl. Geophy. In press.

Joe, P., B. Scott, C. Doyle, G.A. IsaAc, I. Gultepe, D. Forsyth, S.G. Cober, E. Campos, I. Heckman, N. Donaldson, D. Hudak, R. Rasmussen, R.E. Stewart, J.M. Thériault, H. Carmichael, M. BAILEY, and F.S. BoudALA, 2012: The monitoring network of the Vancouver 2010 Olympics. J. Pure Appl. Geophy. In press.

KNIGHT, C. A., 1979: Observations of the morphology of melting snow. J. Atmos. Sci., 36, 1123-1130.

Kong, F., M. Xue, K. Brewster, X. Wang, K. W. Thomas, Y. Wang, S. J. Weiss, A. J. Clark, J. S. Kain, 2011: Storm-scale ensemble forecasting for the NOAA Hazardous Weather Testbed. Sixth European Conf. on Severe Storms, Palma de Mallorca, Spain, Paper \#171.

Lin, Y. L., R. FARLEY, and H. D. ORville, 1983: Bulk parameterization of the snow field in a cloud model. J. Climate Appl. Meteor., 22, 1065-1092.

Lin, Y., B. A. Colle, 2009: The 4-5 December 2001 IMPROVE-2 Event: Observed microphysics and comparisons with the Weather Research and Forecasting model. Mon. Wea. Rev., 137, 1372-1392.

Lin, Y., B. A. Colle, 2011: A new bulk microphysical scheme that includes riming intensity and temperature-dependent ice characteristics. Mon. Wea. Rev., 139, 1013-1035.

Liu, C., K. Ikeda, G. Thompson, R. Rasmussen, J. Dudhia, 2011: High-resolution simulations of wintertime precipitation in the Colorado Headwaters region: Sensitivity to physics parameterizations. Mon. Wea. Rev., 139, 3533-3553.

Locatelli, J. D., and P. V. HobBs, 1974: Fall speeds and masses of solid precipitation particles. J. Geophys. Res., 79, 2185-2197.
Mailhot, J., J.A. Milbrandt, A. Giguère, R. McTaggart-Cowan, A. Erfani, B. Denis, A. Glazer, and M. Vallée, 2012: An experimental $1-\mathrm{km}$ resolution forecast model during the Vancouver 2010 Winter Olympic and Paralympic Games. J. Pure Appl. Geophy. In press.

Meyers, M. P., R. L. Walko, J. Y. Harrington, and W. R. Cotton, 1997: New RAMS cloud microphysics. Part II: The two-moment scheme. Atmos. Res., 45, 3-39.

Milbrandt, J. A. and M. K. YAu, 2005a: A multimoment bulk microphysics parameterization. Part I: Analysis of the role of the spectral shape parameter. J. Atmos. Sci., 62, 3051-3064.

Milbrandt, J. A. and M. K. YAU, 2005b: A multimoment bulk microphysics parameterization. Part II: A proposed three-moment closure and scheme description. J. Atmos. Sci., 62, 3065-3081.

Milbrandt, J. A. and M. K. YAu, 2006: A multimoment bulk microphysics parameterization. Part IV: Sensitivity experiments. J. Atmos. Sci., 63, 3137-3159.

Milbrandt, J. A., M. K. Yau, J. Mailhot, S. Bélair, and R. McTaggart-Cowan 2010: Simulation of an orographic precipitation event during IMPROVE-2. Part II: Sensitivity to the number of moments in the bulk microphysics scheme. Mon. Wea. Rev., 138, 625-642.

Milbrandt, J. A. and R. McTaggart-Cowan, 2010: Sedimentation error in bulk microphysics schemes. J. Atmos. Sci., 67, 3931-3948.

Milbrandt, J. A., A. Glazer, D. JасOB, 2012: Predicting the snowto-liquid ratio of surface precipitation using a bulk microphysics scheme. Mon. Wea. Rev., 24, 2461-2476.

Mitchell, D. L., 1996: Use of mass- and area-dimensional power laws for determining precipitation particle terminal velocities. J. Atmos. Sci., 53, 1710-1723.

Morrison, H. and J. A. Milbrandt, 2011: Comparison of twomoment bulk microphysics schemes in idealized supercell thunderstorm simulations. Mon. Wea. Rev., 139, 1103-1130.

Morrison, H., Thompson, and V. TATARski, 2009: Impact of cloud microphysics on the development of trailing stratiform precipitation in a simulated squall line: Comparisons of one- and twomoment schemes. Mon. Wea. Rev., 137, 991-1007.

Morrison, H., J. A. Curry, and V. I. Khvorostyanov, 2005: A new double-moment microphysics parameterization for application in cloud and climate models. Part I: Description. J. Atmos. Sci., 62, 1665-1677.

PASSARelli, R. E., JR., 1978: An approximate analytical model of the vapour deposition and aggregation growth of snowflakes. J. Atmos. Sci., 35, 118-124.

SEIFERT, A. and K. D. Beheng, 2001: A double-moment parameterization for simulating autoconversion, accretion and selfcollection. Atmos. Res., 59-60, 265-292.

Sмiтн, P. L., 1984: Equivalent radar reflectivity factors for snow and ice particles. J. Climate Appl. Meteor., 23, 1258-1260.

ThÉriault, J., R. E. Stewart, 2010: A parameterization of the microphysical processes forming many types of winter precipitation. J. Atmos. Sci., 67, 1492-1508.

Thériault, J., Rasmussen, T. Smith, M. Brugman, J. Milbrandt, R. Mo, G. IsaAc, P. Joe, J. Mallhot, and B. Denis, 2012: A case study of diabatic cooling of melting snow during the 2010 Vancouver Olympics. Mon. Wea. Rev. (in press).

Thompson, G., R. R. Rasmussen, and K. Manning, 2004: Explicit forecasts of winter precipitation using an improved bulk microphysics scheme. Part I: Description and sensitivity analysis. Mon. Wea. Rev., 132, 519-542. 
Thompson, G., P. H, Field, R. M. Rasmussen, W. D. Hall, 2008 Explicit forecasts of winter precipitation using an improved bulk microphysics scheme. Part II: Implementation of a new snow parameterization. Mon. Wea. Rev., 136, 5095-5115.

Walko, R. L., Wr. R. Cotton, M. P. Meyers, and J. Y. HarringTON, 1995: New RAMS cloud microphysics. Part I: The onemoment scheme. Atmos. Res., 38, 29-62.
Westbrook, C. D., R. J. Hogan, and A. J. Illingworth, 2008: The capacitance of pristine ice crystals and aggregate snowflakes. J. Atmos. Sci., 65, 206-219.

Wu, L. and G. W. PetTy, 2010: Intercomparison of bulk microphysics schemes for model simulations of polar lows. Mon. Wea. Rev., 138, 2211-2228.

(Received February 22, 2012, revised July 4, 2012, accepted July 5, 2012, Published online August 10, 2012) 